\title{
New Investor Class Program Sebagai Sarana Literasi Dan Inklusi Pasar Modal
}

\author{
Tine Badriatin ${ }^{1}$, Lucky Radi Rinandiyana ${ }^{2}$ \\ 1,2Universitas Siliwangi \\ Email: tinebadriatin@gmail.com¹, luckyradi@unsil.ac.id ${ }^{2}$
}

\begin{abstract}
ABSTRAK
Adanya ketertarikan dari akademisi dan masyarakat untuk menjadi investor pasar modal di Bursa Efek Indonesia, namun tanpa dukungan dan pengetahuan tentang apa dan bagaimana cara berinvestasi di pasar modal. Hal ini menjadikan latar belakang pengabdian pada masyarakat untuk edukasi literasi dan inklusi pasar modal.Maka dari itu untuk mendukung hal tersebut diadakan program NICP (New Investor Class Program) yang diselenggarakan oleh PT. Reliance Sekuritas Indonesia, Tbk melalui GIBEI-FE UNSIL-RELI.Program ini bertujuan untuk mengedukasi secara menyeluruh mengenai literasi dan inklusi pasar modal untuk menjadi seorang investor yang berkualitas di pasar modal dan tentunya dapat meningkatkan jumlah investor pasar modal khususnya di Kota Tasikmalaya. Luaran kegiatan program ini adalah kemampuan menangkap peluang Investor dan calon investor pada kegiatan kuliah umum pasar modal serta pengenalan pasar modal pada seluruh kalangan masyarakat, peningkatan pengetahuan Investor/calon investor serta kalangan masyarakat akan pasar modal, Peningkatan Jumlah Investor dalam pembukaan rekening saham, Peningkatan pengetahuan dan kemampuan dalam berinvestasi di Pasar Modal
\end{abstract}

Kata Kunci: bursa efek Indonesia; inklusi; literasi; pasar modal.

\section{ABSTRACT}

There is interest from academics and the public to become capital market investors in the Indonesia Stock Exchange, but without the support and knowledge of what and how to invest in the capital market. This makes the background of community service for literacy education and capital market inclusion. Therefore to support this, a NICP (New Investor Class Program) program is held by PT. Reliance Sekuritas Indonesia, Tbk through GIBEI-FE UNSIL-RELI. This program aims to thoroughly educate the literacy and capital market inclusion to become a quality investor in the capital market and can certainly increase the number of capital market investors, especially in the City of Tasikmalaya. The output of this program is the ability to capture the opportunities of investors and prospective investors in capital market public lectures and the introduction of capital markets to all people, increase investor / prospective investor knowledge and the public about the capital market, increase the number of investors in opening stock accounts, increase knowledge and the ability to invest in the Capital Market.

Keywords: capital market; inclusion; Indonesia stock exchange; literacy.

PENDAHULUAN

Yang menjadi latar belakang diadakannya program NICP ini adalah adanya ketertarikan dari akademisi dan masyarakat untuk menjadi seorang investor namun tanpa dukungan pengetahuan tentang berinvestasi di Pasar Modal Indonesia (IDX). Oleh karena itu program ini bertujuan untuk memberikan pengetahuan tentang bagaimana berinvestasi khususnya Investasi di 
Pasar Modal Indonesia (IDX), meningkatkan informasi dan pengetahuan seputar investasi dikalangan profesional, pengusaha, ibu rumah tangga, kelompok ibu-ibu arisan, akademisi, pensiunan, dan masyarakat umum lainnya, diutamakan yang belum pernah menjadi investor Pasar Modal, memberikan edukasi dan pemahaman yang benar mengenai investasi di pasar modal, menyiapkan program ini agar para investor pemula lebih paham dan mengerti tentang pasar modal serta meningkatkan jumlah investor untuk pasar modal Indonesia.

Masih kurangnya pengetahuan dan pemahaman tentang pasar modal di Kota Tasikmalaya khususnya menjadikan perlunya edukasi dan literasi pasar modal di kalangan masyarakat Kota Tasikmalaya. Hal ini dilihat dari survey penelitian dari data yang diperoleh pada PT. Reliance Sekuritas Indonesia, Tbk Kantor Perwakilan Tasikmalaya (2019) pertumbuhan jumlah investor dari mulai masuknya sekuritas di Kota Tasikmalaya sejak 2004 pada saat itu PT. Valbury Asia Sekuritas kemudian mulai berdiri beberapa sekuritas diantaranya PT. Sarijaya Sekuritas, PT. BNI Sekuritas, PT. Danareksa Sekuritas, PT. CIMB Sekuritas, PT. Reliance Sekuritas Indonesia, Tbk, PT. Sinarmas Sekuritas, PT. Dhanawibawa Sekuritas, PT. Mega Capital Sekuritas sampai 2015 masih stagnan dengan jumlah investor tidak lebih dari 500 investor aktif. Karena bertumbuhan jumlah investor pasar modal yang stagnan tersebut menjadikan beberapa sekuritas akhirnya menutup kantor perwakilan di Kota Tasikmalaya hingga akhirnya sampai tahun 2019 ini hanya tersisa 4 kantor sekuritas di Kota Tasikmalaya.

Mahalnya biaya awal untuk opening account juga menjadi salah satu kendala sulitnya masuk semua kalangan untuk berinvestasi di pasar modal yaitu Rp. 25.000.000 untuk penyetoran awal buka rekening saat itu.Seiring perkembangannya untuk memudahkan dan merangkul semua kalangan agar bisa berinvestasi di pasar modal maka dengan Rp. 100.000 masyarakat sudah bisa menjadi seorang investor. Investasi sendiri menurut Martalena dan Maya Malinda (2011) merupakan bentuk penundaan konsumsi masa sekarang untuk memperoleh konsumsi dimasa yang akan dating, namun demikian terdapat unsur resiko.

Oleh karena itu program pengabdian pada masyarakat melalui program NICP ini diharapkan dapat menjadi salah satu sarana edukasi pada masyarakat bahwa investasi di pasar modal itu mudah dan terjangkau. Program ini bekerja sama dengan PT. Reliance Sekuritas Indonesia, Tbk. Sebagai salah satu anggota Bursa Efek Indonesia yang nantinya dapat membantu masyarakat dalam pembukaan rekening efek dimana telah bekerja sama dengan Fakultas Ekonomi Universitas Siliwangi dan Bursa Efek Indonesia dengan didirikannya Galeri Investasi (GIBEI-FE UNSIL-RELI). GIBEIFE UNSIL-RELI ini sebagai salah 
satu sarana edukasi pasar modal tidak hanya untuk kalangan akademisi namun juga masyarakat umum.

Menurut penelitian sebelumnya (Ferry Khusnul Mubarok : 2018) menunjukkan bahwa sosialisasi dan edukasi kepada mahasiswa melibatkan berbagai informan diantaranya meliputi teman, dosen, pengurus galeri investasi, seminar, kuliah dan media social. Sementara itu Literasi menurut POJK No.76/POJK.07/2016 adalah ketersediaan akses pada berbagai Lembaga, produk dan layanan jasa keuangan sesuai dengan kebutuhan dan kemampuan masyarakat dalam rangka meningkatkan kesejahteraan masyarakat. Sedangkan Inklusi menurut POJK No.76/POJK.07/2016 adalah ketersediaan akses pada berbagai Lembaga, produk dan layanan jasa keuangan sesuai dengan kebutuhan dan kemampuan masyarakat dalam rangka meningkatkan kesejahteraan masyarakat.

\section{METODE PENELITIAN}

Program pengabdian pelayanan masyarakat melalui edukasi, sosialisasi dan literasi serta inklusi pasar modal yang diselenggarakan oleh PT. Reliance Sekuritas Indonesia, Tbk kantor perwakilan Tasikmalaya melalui GIBEI-FE UNSIL-RELI ini dilaksanakan melalui program New Investor Class Program (NICP) dengan tema "New Investor Class Program sebagai sarana untuk meningkatkan literasi dan Inklusi Pasar Modal pada
Mahasiswa Fakultas Ekonomi Universitas Siliwangi melalui GIBEIFE UNSIL-RELI”. Program ini dilaksanakan dengan menggunakan :

1. Metode Seminar

Seminar merupakan kegiatan proses pemecahan suatu masalah atau penemuan cara atau langkah suatu pengembangan yang biasanya diangkat dari hasil kajian literatur atau empiric (Hari Ryanto Wiyono, Bima Cahya Putra : 2018). Seminar Pasar Modal yang diberikan kepada Mahasiswa Fakultas Ekonomi Universitas Siliwangi mempunyai tujuan untuk meningkatkan pengetahuan tentang pasar modal dikalangan generasi muda khususnya mahasiswa Fakultas Ekonomi Universitas Siliwangi.

Seminar yang diberikan kepada mahasiswa melalui seminar Pasar modal dan Kuliah Umum kepada Mahasiswa Fakultas Ekonomi Universitas Siliwangi yang diselenggarakan di GIBEI-FE UNSIL-RELI

2. Metode Pelatihan

Menurut Veithzal pelatihan adalah proses secara sistematis mengubah tingkah laku pelaku usaha untuk mencapai tujuan yang berkaitan dengan keahlian dan kemampuan.

Sejalan dengan semangat memajukan Pasar Modal Indonesia, serta dalam rangka meningkatkan pengetahuan dan informasi yang benar dan tepat tentang investasi, PT Reliance Sekuritas Indonesia, Tbk Kantor Perwakilan Tasikmalaya melalui GIBEI-FE UNSIL-RELI 
mengadakan sosialisasi dan edukasi Pasar Modal kepada masyarakat lewat pelatihan pasar modal gratis yang diberi nama NICP. Seminar yang diberikan kepada mahasiswa diberikan tidak hanya cukup satu kali saja maka dengan Program NICP ini bertujuan memberikan pengetahuan tentang Berinvestasi khususnya Investasi di Pasar Modal Indonesia (IDX).

Program NICP ini dilaksanakan selama 3 bulan untuk setiap batch, dimana peserta minimal 10 orang untuk setiap batch nya. Program ini dilaksanakan selama 6 bulan terhitung dari 1 November 2018 - 30 April 2019

\section{Mengingat pemahaman} masyarakat tentang pasar modal saat ini masih belum merata dan masih banyak yang belum memahami bagaimana cara berinvestasi di pasar modal, maka PT BEI menyelenggarakan Sekolah Pasar Modal (SPM) yang diharapkan dapat menampung, merangsang, dan mengarahkan animo masyarakat yang berminat untuk menekuni pasar modal sebagai media investasinya.

Tujuan dari kegiatan ini adalah memberikan edukasi menyeluruh kepada peserta mengenai investasi di Pasar Modal. Edukasi yang diberikan dilakukan secara bertahap, mulai dari Level 1 dan Level 2 Program Reguler serta Level 1 dan Level 2 Program Syariah, Mempersiapkan para peserta Sekolah Pasar Modal untuk menjadi investor berkualitas di Pasar Modal serta
Meningkatkan jumlah investor di Pasar Modal Indonesia.

Sementara itu yang menjadi target peserta dari kegiatan ini adalah Peserta pelatihan diharapkan berasal dari para profesional, pengusaha, ibu rumah tangga, kelompok ibu-ibu arisan, akademisi, pensiunan, mahasiswa dan masyarakat umum lainnya, diutamakan yang belum pernah menjadi investor Pasar Modal. Target jumlah peserta sekitar 100orang peserta dengan kapasitas 20 orang peserta per batch NICP dan 50 orang peserta per gelombang untuk Sekolah Pasar Modal di GIBEI-FE UNSIL-RELI

\section{HASIL DAN PEMBAHASAN}

Hasil Kegiatan Literasi dan Inklusi Pasar Modal melalui Program NICP (New Investor Class Program) dapat dilihat dari table 1 berikut ini.

Tabel 1.Hasil Kegiatan Literasi dan Inklusi Pasar Modal melalui Program

NICP

\begin{tabular}{|c|l|l|}
\hline Aspek & \multicolumn{1}{|c|}{ Kegiatan } & \multicolumn{1}{|c|}{ Luaran } \\
\hline Literasi & Kuliah & Kemampuan \\
& Umum Pasar & menangkap \\
& Modal & peluang \\
& & Investor dan \\
& calon investor \\
& & pada kegiatan \\
& & kuliah umum \\
& pasar modal \\
& serta \\
& pengenalan \\
& pasar modal \\
& pada seluruh \\
& kalangan \\
& masyarakat \\
& Peningkatan \\
& pengetahuan \\
& Investor/calon \\
& investor serta \\
& kalangan \\
& masyarakat \\
\hline
\end{tabular}




\begin{tabular}{|c|c|c|}
\hline Aspek & Kegiatan & Luaran \\
\hline & & $\begin{array}{ll}\text { akan pasar } \\
\text { modal }\end{array}$ \\
\hline \multirow[t]{2}{*}{$\begin{array}{l}\text { Inklusi } \\
\text { Pasar } \\
\text { Modal }\end{array}$} & \multirow[t]{2}{*}{$\begin{array}{l}\text { Simulasi } \\
\text { Perdagangan } \\
\text { Saham di } \\
\text { Bursa Efek } \\
\text { Indonesia }\end{array}$} & $\begin{array}{l}\text { Peningkatan } \\
\text { Jumlah } \\
\text { Investor } \\
\text { dalam } \\
\text { pembukaan } \\
\text { rekening } \\
\text { saham }\end{array}$ \\
\hline & & $\begin{array}{l}\text { Peningkatan } \\
\text { pengetahuan } \\
\text { dan } \\
\text { kemampuan } \\
\text { dalam } \\
\text { berinvestasi } \\
\text { di Pasar } \\
\text { Modal }\end{array}$ \\
\hline
\end{tabular}

Adapun ringkasan program dari kegiatan pengabdian pada masyarakat ini dapat dilihat dari tabel 2 berikut ini.

Tabel 2. Ringkasan Program NICP

\begin{tabular}{|l|l|l|}
\hline $\begin{array}{l}\text { Nama } \\
\text { Program }\end{array}$ & $:$ & $\begin{array}{l}\text { New Investor Class } \\
\text { Program }\end{array}$ \\
\hline Pengelola & $:$ & $\begin{array}{l}\text { Tim GIBEI-FE } \\
\text { UNSIL-RELI }\end{array}$ \\
\hline Peserta & $:$ & $\begin{array}{l}\text { Investor pemula / } \\
\text { baru (minimal 10 } \\
\text { orang tiap batch) }\end{array}$ \\
\hline Tempat & $: \begin{array}{l}\text { Ruang GIBEI-FE } \\
\text { UNSIL-RELI }\end{array}$ \\
\hline Waktu & $: \begin{array}{l}\text { Senin - Jumat } \\
\text { Jam 09.00 - 16.00 } \\
\text { (sesuai jam market } \\
\text { BEI) }\end{array}$ \\
\hline $\begin{array}{l}\text { Jumlah } \\
\text { pertemuan }\end{array}$ & $: \begin{array}{l}\text { 30 menit x 10 } \\
\text { pertemuan untuk tiap } \\
\text { batch }\end{array}$ \\
\hline Biaya & $\begin{array}{l}\text { Rp. 100.000 (untuk } \\
\text { pembukaan opening } \\
\text { account rekening } \\
\text { efek / reksadana) }\end{array}$ \\
\hline
\end{tabular}

Literasi yang dilakukan adalah melalui kegiatan kuliah umum dimana dalam kuliah umum ini mampu menangkap peluang investor dan calon investor serta pengenalan pasar modal kepada kalangan masyarakat.

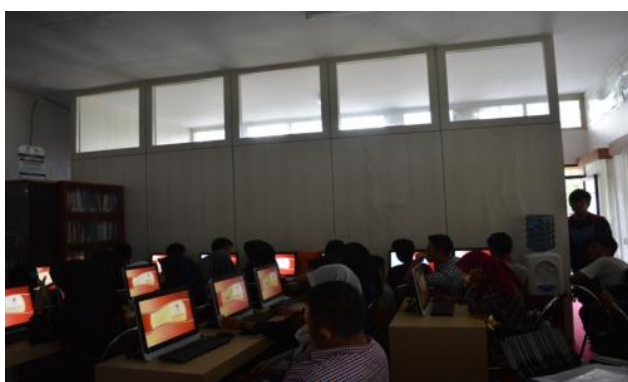

Gambar 1. Kuliah Umum Pasar modal di GIBEI-FE UNSIL-RELI

Program NICP ini juga didukung oleh Otoritas Jasa Keuangan Kantor Tasikmalaya, dimana pada saat pembukaan program ini dibuka sekaligus memberikan materi mengenai perlindungan OJK terhadap investor pasar modal sehingga memberikan keyakinan akan investasi yang aman di pasar modal terhadap masyarakat atau calon investor.

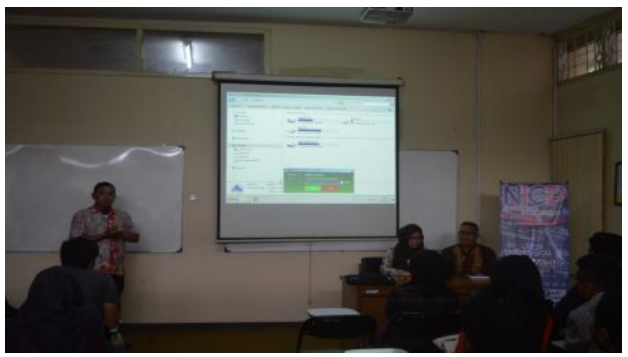

Gambar 2 . Pembukaan NICP

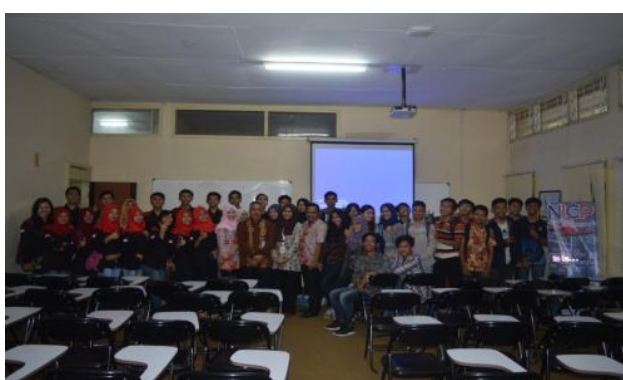

Gambar 3. Peserta Batch pertama Program NICP

Adapun materi yang diberikan pada program NICP ini adalah sebagai berikut.

Tabel 3. Silabus NICP 


\begin{tabular}{|l|l|}
\hline No. & \multicolumn{1}{|c|}{ Materi NICP } \\
\hline 1. & Perkenalan GIBEI-FE UNSIL- \\
RELI
\end{tabular}

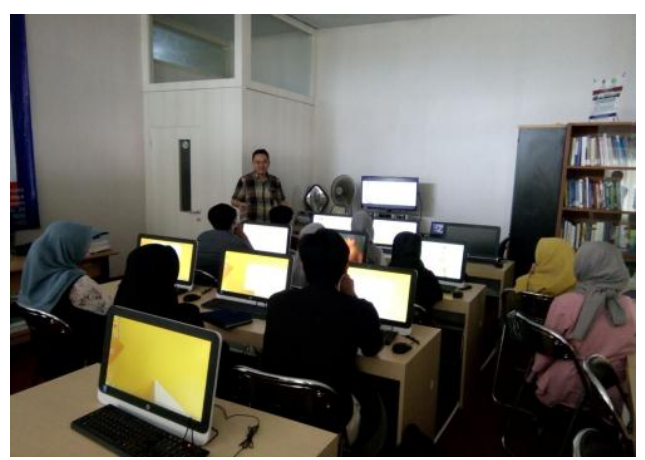

Gambar 4. Pengenalan Materi Pasar Modal pada peserta NICP

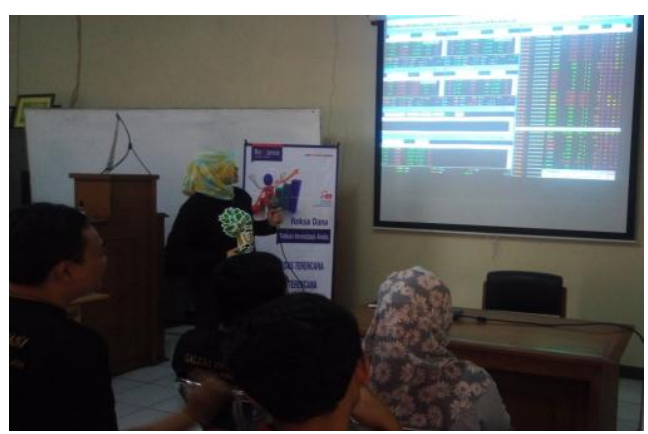

Gambar 5. Materi Pengenalan

Simulasi Perdagangan Saham di

Bursa Efek Indonesia

Hasil nyata dalam kegiatan praktek perdagangan saham di Bursa Efek Indonesia melalui program NICP ini, bahwa peserta mendapat pengetahuan dalam berinvestasi di pasar modal.

Pada dasarnya selama program New Investor Class, peserta sangat antusias dan pro aktif dengan adanya kegiatan tersebut, serta menginginkan kegiatan yang bersifat berkelanjutan. Bahkan beberapa diantaranya sudah dapat merasakan keuntungan berinvestasi di pasar modal. Disamping hasil yang dinilai positif, sebetulnya pelaksanaan kegiatan New Investor Class Program tersebut masih banyak kekurangan serta hambatannya, sebagai contoh dalam penerapan aplikasi online melalui Relitrade terkendala dengan jaringan koneksi internet yang kurang stabil, dana untuk investasi yang terbatas, serta alat pendukung lainnya dalam proses perlaksanaan perdagangan saham melalui dealer seperti harus tersedianya perangkat rekaman order, blotter pembelian/penjualan serta menunggu proses rekening jadi.

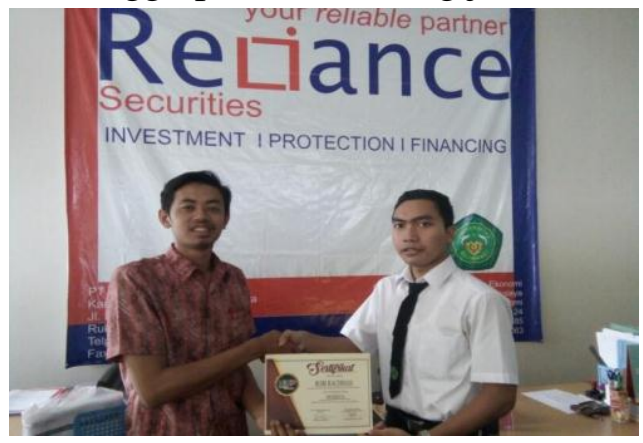

Gambar 6. Penyerahan Sertifikat Program NICP

\section{SIMPULAN}

Dari pelaksanaan kegiatan NICP (New Investor Class Program) dalam rangka pengabdian kepada masyarakat khususnya kalangan mahasiswa di Fakultas Ekonomi 
Universitas Siliwangi dan Mahasiswa pada Perguruan Tinggi yang ada di Kota Tasikmalaya secara garis besar dapat disimpulkan bahwa:

1. peserta belum pernah mendapat pengetahuan dan materi tentang pasar modal serta penerapan aplikasinya dalam perdagangan saham di Bursa Efek Indonesia.

2. peserta mempunyai motivasi tinggi, apalagi setelah diberikan materi simulasi perdagangan saham di Pasar Modal melalui online trading Relitrade di GIBEIFE UNSIL-RELI.

3. mendukung adanya kegiatan serupa dimasa mendatang.

4. diperlukan adanya pelatihan berkelanjutan serta praktek langsung dalam perdagangan pasar modal dengan cara membuka opening account terlebih dahulu. Dalam hal ini GIBEI-FE UNSIL-RELI telah bekerja sama dengan PT. Reliance Sekuritas Indonesia, Tbk untuk proses pembukaan rekening saham

Namun demikina atas hasil yang dicapai sampai saat ini sebagai pertimbangan pelaksanaan kegiatan pengabdian pada masyarakat dimasa mendatang melalui GIBEI-FE UNSIL-RELI, yakni perlu pengaturan jadwal kegiatan yang tepat sesuai kondisi dan situasi serta berkelanjutan serta perlu ada peningkatan kegiatan yang bersifat praktek seperti sosialisasi melalui Relitrade.
DAFTAR PUSTAKA

Davis, Keith (1986). Personal Management and Human Resource. ${ }^{\text {ed }}$. Singapore: McGraw Hill Book Company.

Fahmi dan Hadi (2009).Pasar Modal dan Manajemen Portofolio.Jakarta : Erlangga.

Ferry Khusnul Mubarok. (2018). Peran Sosialisasi dan Edukasi dalam Menumbuhkan Minat Investasi di Pasar Modal Syariah. UIN Walisongo, Semarang. Jurnal Inovasi, Vol.14, No. 2. 113-122.

Hari Ryanto Wiyono, Bima Cahya Putra. (2018). Perancangan Sistem Informasi Pengolahan Data Seminar Berbasis Desktop pada CV. Dhifarindo Bekasi dengan Menggunakan Metode Berorientasi Obyek Universitas Budi Luhur, Jurnal IDEALIS, Vol.1, No.3, Juli 2018. 273-279.

https://www.idx.co.id/investor/caramenjadi-investor/

$\begin{array}{cr}\text { Martalena dan } & \text { Malinda } \\ \text { (2011).Pengantar } & \text { Pasar } \\ \text { Modal. Yogyakarta: Andi }\end{array}$

Otoritas Jasa Keuangan (2017). Survei Nasional Literasi dan Inklusi Keuangan 2016.

Peraturan Otoritas Jasa Keuangan. (2016). Peningkatan Literasi dan Inklusi Keuangan di Sektor Jasa Keuangan bagi Konsumen dan/atau Masyarakat. Nomor 76/POJK.07/2016.

Sikapiuangmu.ojk.go.id 
Tine Badriatin', Lucky Radi Rinandiyana²/ Aksiologiya: Jurnal Pengabdian Kepada Masyarakat. Vol.4, No.1, Februari 2020 Hal 100-107

Sunariyah (2011).Pengantar

Pengetahuan Pasar

Modal.Yogyakarta : UPP STIM YPKN.

Veitzal Rivai. (2010). Manajemen

Sumber Daya Manusia Untuk

Perusahaan.Cetakan ke-3.

Jakarta: PT. Raja Grafindo

Persada.

https://www.ojk.go.id/id/kanal/pasarmodal/berita-dan-

kegiatan/info-

terkini/Pages/Sosialisasi-dan-

Edukasi-Pasar-Modal-Terpadu-

2016.aspx

https://www.idx.co.id

https://www.reliancesekuritas.com 